even if this favourite device were admissible, would give a satisfactory explanation of the contrast between the past and the present.

Discarding as inadequate, and as a method wholly displeasing to astronomers, an attempt to create geographical environment consistent with palæobotanical facts by altering the position of the north pole, we turn to the alternative of rearranging, within the Arctic circle, the distribution of land and sea and the consequential shifting of cold and warm oceanic streams. Dr. C. E. P. Brooks suggests a possible rearrangement of land and water which, he believes, would go some way towards the provision of climatic conditions such as the fossil plants of the Tertiary period appear to demand; but it would seem from a more recent contribution by Dr. G. C. Simpson that we cannot hope to obtain all we need, or nearly all we need, by any method of redistribution of land and sea on the assumption of a fixed pole, and without recourse to Wegener's hypothesis of drifting land areas.

We are left with two other alternatives: the adoption of Wegener's views or some modification of them; or the possibility that plants are less trustworthy as indices of climates than has generally been supposed. It may be that a combination of these two methods of attack is the clue to our problem. Let us take the second first : assuming that the ferns to which reference has been made flourished on the parallels of latitude where their remains have been found, and assuming such amelioration of the present Arctic conditions by a rearrangement of land and water as meteorologists permit, there must have been in the past, as there is to-day, a long and relatively dark period of sleep, and a summer no longer than the growing season now available for the almost miraculous development of Arctic plants. Can we imagine, to take one instance, the Cretaceous flora of Greenland enduring a sunless Arctic night more than six months in duration?

There is another, and to my mind an important and neglected consideration; we are too prone to speak of such a genus as Gleichenia as tropical because it happens to be one of the commoner ferns in tropical countries; but like many other genera characteristic of the warmer parts of the world, it includes species which grow vigorously at an altitude of $10,000 \mathrm{ft} .-12,000 \mathrm{ft}$. where the climate is by no means tropical. Is it not legitimate to suggest that a plant that is now confined to the tropics may at a much earlier stage of its career have been able to live under other conditions ? Is it unscientific to express the opinion that we may think of plants not only as organisms which have changed in form and structure in the course of thousands or millions of years, but also as organisms which have changed in their susceptibility to external factors?

I suggest that there is a tendency to rate too highly the value of extinct plants as guides to climatic conditions, and I would emphasise the desirability of obtaining more definite information than is at present available on the effect of continuous light and continuous darkness, under suitable temperatures, on plants which do not at present occur in Arctic habitats. Even if the foregoing suggestions have any merit, and if we have underestimated the capacity of plants to survive Arctic seasons, there is still a serious obstacle to surmount before it is possible to imagine, let us say, the Rhætic vegetation of Scoresby Sound and that of southern Sweden flourishing in regions separated from one another by at least ten degrees of latitude.

Wegener speaks of the upper portion of the earth's crust as travelling in an easterly and westerly direction; he also assumes a slight movement of the poles. If it is permissible to postulate a drifting of fractured slabs of the crust in a north and south direction, we can then think of the disunited pieces, now occupying positions more or less remote from one another, as the severed portions of a formerly compact region. To take a concrete example : the Rhætic plant beds of eastern Greenland, now remote from those of Sweden, may formerly have been portions of one mass well to the south of the Arctic circle. This may be merely a figment of the imagination; but such evidence of correspondence, both in the succession and nature of the stratified rocks and in the fossil contents, as Mr. Du Toit has obtained from a comparative study of the rocks of South America and South Africa, or as Mr. Harris is finding in his comparison of the Greenland and Swedish Rhætic strata, is arresting enough to make us pause before abandoning the principle of continental drift.

\section{Palmobotany as a Key to the Present Distribution of Plants.}

If time allowed it would be tempting to deal with still another aspect of palæobotany; the importance of a critical study of the floras which immediately preceded the Pleistocene Ice Age. Progress made in recent years in the improvement of methods of deciphering the relics of plants of other days increases the confidence with which it is possible to recommend, as a promising field of work, the investigation of Tertiary floras. The Tertiary floras were more uniform than the floras of to-day. We cannot understand the present distribution of human races if we confine attention to the present, nor can we appreciate the significance of the geographical distribution of floras and their composition unless we consult the herbaria of the rocks.

\title{
Low Frequency Sound Waves and the Upper Atmosphere.
}

\section{By E. H. Gowar.}

THE transmission of low frequency sound waves, such as those from explosions, to very great distances has been an accepted fact for some time, but for careful investigations it was inevitable that mechanical instruments should eventually replace the ear in receiving the waves. These instruments have the advantage of being more certain, more accurate, and of producing a permanent record. Some types show the form of the wave, and all are more sensitive to the longer wavelengths which may be completely missed by the ear, even though they are not quite outside the

No. 3125, VoL. 124] 
audible limit. Those beyond this limit are actually the more useful because they tend to be less strongly absorbed in their passage through the air.

One of the most important instruments used is the hot wire microphone. A suitable closed box has in one wall a small orifice in which is placed a fine wire coil, heated by an electric current. This filament forms one arm of a sensitive resistance bridge, of which disturbances of balance can be shown by a short period recording galvanometer. The passage of a wave causes a draught to flow in and out of the orifice, cools the wire, thus changing its resistance and destroying the balance of the bridge. A moving film shows the deflection of the galvanometer beside time marks which are recorded automatically at suitable intervals.

Another recording instrument is the undograph, which has received wide use and commendation in Germany. A steel fibre is fastened to a thin mica sheet along an axis of symmetry, and is arranged to act as a taut suspension. The sheet swings freely, one half, with as little clearance as possible, in an opening through the wall of a large air-tight box; the other half swings in a small chamber, providing some damping, but is protected from the incoming wave. The motion is shown by a beam of light reflected from a mirror on the mica, and the optical, mechanical, and photographic arrangements for recording this, along with the necessary time marks, are all contained inside the box. The natural period of the system is of the order of a second, and the records obtained from waves just below the audible limit are very good, and easily distinguishable from accidental and wind disturbances because they are approximately sinusoidal.

A comparison of the two instruments shows that there is not much to choose between them in the matter of maximum sensitivity, though the undograph is less disturbed by wind and other accidental causes, and can perhaps be used in an adjustment nearer its maximum. The microphone gives a non-symmetrical record and does not show up the form of the wave. On account of greater complication it is only with difficulty made portable, but the undograph is very conveniently selfcontained. The fact that the undograph is much the cheaper instrument is perhaps after all the greatest point in its favour.

A large body of observations has resulted from great activity in Germany, ${ }^{1}$ culminating in a systematic series of experiments under the Notgemeinschaft der Deutschen Wissenschaft. Early results indicated a marked seasonal effect, the minimum distance at which sound was heard in the outer zone being $110 \mathrm{~km}$. in winter and 190 $\mathrm{km}$. in summer. Corresponding distances for maximum intensity were $125 \mathrm{~km}$. and $230 \mathrm{~km}$. The later results followed a searching investigation of the effect on the consistency of the observations

${ }^{1}$ British observers have in the past few years been working with the hot wire microphone, registering the waves from experimental gunfire in any detail here. On p. 114 of the second report of the Committee on Solar and Terrestrial Relationships, International Research Council,
will be found an admirable summary by Dr. F. J. W. Whipple.

No. 3125, VoL. 124] of kind and amount of explosive, its position with respect to the ground, the nature of the soil, and methods of detonation. The velocity for the inner zone is normal for the temperature of the air at the ground, $330-340 \mathrm{~m}$./sec., but the apparent velocity for the outer zone is lower than this, $280-300 \mathrm{~m}$./ $/ \mathrm{sec}$. The conclusion is that the sound has travelled a much longer path through the upper atmosphere. In different directions from the source of the wave the time of travel to the same distance in the outer zone varies by so much as 35 sec. This is attributed to upper air winds. It can be shown that the apparent surface velocity of the returned ray, measured by means of two instruments grouped a few hundred metres apart, on a line containing the source, is equal to the velocity at the highest point of the trajectory. As one also knows, from the interval between reception at the two instruments, the angle at which the ray comes down, an estimate of the height is possible. The average results of several methods of analysis show that at about $40 \mathrm{~km}$. the velocity must be in the neighbourhood of $340 \mathrm{~m}$. $/ \mathrm{sec}$.

Several theories have been put forward to account for the existence of one or more zones of abnormal audibility. The effect was at first ascribed to strong winds in the stratosphere, but so soon as it was established that waves were received in all directions, this idea was abandoned as untenable. It was next suggested that the increase in velocity was due to a settling out of the heavier gases and the relative predominance of hydrogen and helium at the heights where bending takes place. From other considerations, however, it seems unlikely that there is much change in composition below $80-100 \mathrm{~km}$. Even if 25 per cent of the lighter gases were possible at $50 \mathrm{~km}$., the time of travel is not sufficient for the wave to reach the necessary height, and also the diminution of intensity would be too great in passing through regions of such low pressures.

The ordinary formula for the velocity of sound in a gas is valid only if the amplitude of the wave is small in comparison with the total pressure. If this is not so the values are much greater, and in the immediate vicinity of explosions, velocities so great as $900 \mathrm{~m} . / \mathrm{sec}$. have been observed. It has been claimed that the velocity increase in the upper regions is due to such a breakdown of the ordinary formula, but it is perhaps doubtful that the total pressure falls off more rapidly with height than the amplitude falls off with distance from the source, when the smallness of the average angle is considered. Though this last explanation may perhaps claim a share of the responsibility, and cannot be peremptorily dismissed, another has been more widely accepted as being primarily responsible. The supposition that above $30 \mathrm{~km}$. the temperature of the atmosphere increases again with height until it reaches, or even surpasses, ground temperature, is sufficient in itself to account for the abnormal zone of audibility. The abovementioned velocity of $340 \mathrm{~m}$. $/ \mathrm{sec}$. at $40 \mathrm{~km}$. indicates a temperature of about $15^{\circ} \mathrm{C}$. there. Such 
high temperatures in the upper atmosphere were first indicated by a study of meteors, and it has recently been shown that the absorption of solar energy in the ozone layer (centre of gravity about $45-50 \mathrm{~km}$.) is responsible for their maintenance. This explanation, supported as it is by evidence from two independent sources, seems likely to remain as the most important in the field.

The experimental investigation of conditions in the upper air is full of difficulty, and one of the most fruitful and powerful methods seems to be by the use of these low frequency sound waves. The institution of consistent and systematic explosions to be observed by registering instruments in groups of two as above, spaced, say, $10 \mathrm{~km}$. apart so as to cover the whole abnormal zone on a suitably chosen diameter (with the addition, if feasible, of a radius at right angles), could give much information about the seasonal and possible diurnal variation of the radius of the inner edge. Perhaps a simpler method of getting information about the upper winds would be the grouping of three instruments in a triangle, a few hundred metres apart, enabling both the vertical and horizontal angles to be measured. A most important step is to have work of this sort undertaken at representative and suitable parts of the world. Increases in our knowledge of the physics of the upper air are almost certain to result from the co-operation of workers in various countries, once the highly important problem of defraying the cost is solved.

\section{Obituary.}

DR. W. G. DufField.

$\mathrm{T}^{\mathrm{T}}$ is but a few weeks ago that we were giving a welcome to the first publication (Memoirs, vol. i. No. 1), issued from the Solar Observatory of the Australian Commonwealth, at Canberra; and now to our deep regret comes the news of the death, on Aug. I after a brief illness, of Dr.Walter Geoffrey Duffield, the Director of the Observatory.

Dr. Duffield was the son of the late Mr. W. Duffield of Adelaide, and a grandson of Senator Walter Duffield, one of the first members of the South Australian Parliament. He graduated first at the University of Adelaide in 1900, and then at Cambridge, where he passed out in the Mechanical Sciences Tripos in 1903. He married Miss Doris Boult, of Adelaide. Later, at the University of Manchester, from which he received the degree of D.Sc. in 1908, he became an honorary research fellow, and worked at the subject of the effect of pressure upon arc spectra. He held a Mackinnon Studentship awarded by the Royal Society in the years 1906 and 1907, and under the stimulating influence of Sir Arthur Schuster he communicated four memoirs on the subject named above to the Transactions of the Royal Society in the years 1907-15, extending thereby the work of Humphreys and Mohler, especially in relation to the metals iron, copper, silver, gold, and nickel, and studying the arc spectra of those metals at pressures ranging from 1 atmosphere to 101 atmospheres.

In 1911, Duffield was appointed to the professorship of physics at University College, Reading, a post which he held until 1923. Though the claims on his time and energies were considerable, both as professor and as dean of the Faculty of Science, he found time for research work and for encouraging such work amongst his post-graduate students. Among other subjects he studied the electric carbon arc from the point of view of the consumption of carbon under varied conditions of current strength and length of arc, and their influence on the luminosity of the arc. Papers on the subject were published in the Proceedings of the Royal Society, vol. 92.

In 1912, Duffield had discovered the existence of minute repulsion between the poles of an electric carbon arc. Seven years later he carried out, with the assistance of two of his post-graduate students, a beautiful set of experiments designed to eliminate all extraneous disturbing forces. $\mathrm{He}$ succeeded in measuring the outstanding force of repulsion though it was only of the order of a dyne, and showed that it was due to the recoil consequent upon the projection of electrons from the poles (Trans. Roy. Soc., A, vol. 220). A year later he had extended the observations to the case of metal ares.

During the War Duffield served, despite ill health, as captain in the Royal Air Force.

Another piece of Duffield's research work may be mentioned here, namely, his attempt to determine the value of gravity over the ocean, on a voyage to Australia and back, in 1914. His results were published in the Proceedings of the Royal Society, vol. 92. A vivid account of the preparations for the work and the difficulties experienced was given in the report of three pages in the British Association Report for 1915, p. 48. The main object of the research was to obtain results bearing on the theory of isostasy. Duffield showed undaunted perseverance in discovering and remedying leaks in the four barometers which were involved in his operations in the refrigerators of the s.s. Ascanius. The whole-hearted assistance which he evoked from all those with whom he came in contact in his enthusiastic efforts was a splendid testimonial to the fervour of his devotion.

When the British Association in 1908 appointed a committee with Sir David. Gill as chairman to aid the work of establishing a solar observatory in Australia, Dr. Duffield was chosen as secretary. The matter was one requiring considerable tact and perseverance in addition to a knowledge of local politics and local conditions. The first report of the committee was published in the British Association Report for 1909, and contains a statement of the history of the movement. It sets forth the grounds on which the committee urged the participation of Australia in the international cooperation in solar research then in full activity. Dr. Duffield made three voyages to Australia with such good results that in 1914, when the Associa-

No. 3125, VoL. 124] 